\title{
Aluminum-containing Intergranular Phases in Hot-Pressed Silicon Carbide
}

\author{
Xiao Feng Zhang ${ }^{1}$, and Lutgard C. De Jonghe ${ }^{1,2}$ \\ ${ }^{1}$ Materials Sciences Division, \\ Lawrence Berkeley National Laboratory, Berkeley, CA 94720 \\ and \\ ${ }^{2}$ Department of Materials Science and Engineering, University of California at Berkeley, \\ Berkeley, CA 94720
}

\begin{abstract}
Aluminum-containing intergranular phases, forming intergranular films and secondary phase particles at triple-junctions in $\mathrm{SiC}$ hot-pressed with aluminum, boron, and carbon additions, were studied by transmission electron microscopy. Statistical high-resolution electron microscopy study of intergranular films indicated that a large fraction of the vitreous intergranular films in the as-hot-pressed $\mathrm{SiC}$ crystallized during postannealing in argon above $1000^{\circ} \mathrm{C}$. However, brief heating to $1900^{\circ} \mathrm{C}$ indeed re-melted $25 \%$ of the crystallized intergranular films. The structural transitions were reflected in the statistical width distributions of the amorphous grain boundary layers. At triple-junctions, $\mathrm{Al}_{2} \mathrm{O}_{3}, \mathrm{Al}_{2} \mathrm{OC}-\mathrm{SiC}$ solid solution, and mullite phases were newly identified. These phases, together with others reported before are represented in a quaternary phase diagram for $1900^{\circ} \mathrm{C}$. It is proposed that a $\mathrm{SiC}-\mathrm{Al}_{2} \mathrm{OC}$ liquid domain is to be included in this phase diagram.
\end{abstract}

Keywords: Ceramics, Grain boundary structure, TEM 


\section{Introduction}

The covalent nature of $\mathrm{SiC}$ necessitates the use of sintering additives to achieve densification at practical temperatures and pressures. In the early 1950s, Alliegro et al. were among the first to sinter $\mathrm{SiC}$ with suitable sintering additives $\left(\mathrm{Al}_{2} \mathrm{O}_{3}\right.$ or $\left.\mathrm{Al}\right)$ [1]. Later, it was found that hot pressing with boron and carbon additions could lead to a SiC with $96 \%$ of the theoretical density [2], or better [3-4]. While the densification mechanism was not clear, it was already known that boron and carbon did not form intergranular films [5-6] but rather dissolved into the $\mathrm{SiC}$ grains, not supporting a liquid phase densification mechanism. High temperatures, usually above $2000^{\circ} \mathrm{C}$, are required for the solid-phase sintering. Aluminum or Al-containing additives substantially lowered the sintering temperature by as much as $300^{\circ} \mathrm{C}[1,3,4,7-13]$, due to the formation of $\mathrm{Al}-$ rich liquid phases that promote densification [7,14-16]. In fact, a combination of $\mathrm{Al}, \mathrm{B}$ and $\mathrm{C}$ was found to be effective in densifying $\mathrm{SiC}$ at about $1900^{\circ} \mathrm{C}$. Because of the presence of liquid, intergranular phases are expected to form. Al-based oxycarbide grain boundary film between SiC grains were observed [2,7,17-22], as well as other secondary phases at triple junctions [21-23]. The best of these SiC materials yet investigated exhibited unprecedented combinations of strength, fracture toughness, fatigue, high temperature creep resistance, and wear resistance [9,14,17,18,24-31], resulting from the presence of favorable grain boundary structures [22]. In this paper, a statistical transmission electron microscopy (TEM) analysis is reported for the structural changes of the Al-containing intergranular phases in SiC before and after annealing; in addition, secondary phases which were not discussed previously are examined.

\section{Experimental}

Submicron $\beta$-SiC (B20, H. C. Starck, Germany) powder was mixed with 3 wt\% aluminum metal (H-3 and H-10, Valimet, Stockton, CA), 0.6 wt\% boron (Callery Chemical Co, Callery, PA), and 2 wt\% carbon. Apiezon wax (AVO Biddle Instruments, Blue Bell, PA) was dissolved in toluene to serve as the carbon source. $\mathrm{Al}, \mathrm{B}$, and $\beta-\mathrm{SiC}$ powders were added to the solution, and ultrasonically agitated to minimize agglomerate formation. The slurry was stir-dried, and the powder was sieved through a 200 mesh screen. Green compacts were uniaxially pressed at $35 \mathrm{MPa}$. Hot-pressing was performed 
at $1900^{\circ} \mathrm{C}, 50 \mathrm{MPa}$, for 1 hour in argon. The products were highly dense $\left(3.18 \mathrm{~g} / \mathrm{cm}^{3}\right)$, and have been referred to as $\mathrm{ABC}-\mathrm{SiC}[17]$. $4 \mathrm{H}-$ and $6 \mathrm{H}-\mathrm{SiC}$ phases were dominant. Post-annealing was carried out at 1000 to $1500^{\circ} \mathrm{C}$, in $\mathrm{Ar}$, at $100^{\circ} \mathrm{C}$ increments, for times ranging between 3 to 7 days. One specimen was reheated to $1900^{\circ} \mathrm{C}$ for 5 min subsequent to the $1500^{\circ} \mathrm{C}$ heating and cooling, and the changes in the grain boundary film structures was determined.

Structural and chemical characterizations were carried out in a field-emission gun Philips CM200 transmission electron microscope operating at $200 \mathrm{kV}$. For compositional analysis, an energy-dispersive X-ray spectroscopy (EDS) system equipped with a windowless detector was employed. Boron can be detected with this EDS system. Detailed description and discussion for the quantitative EDS analysis method has been published elsewhere [32].

\section{Results}

Fig. 1 shows a high-resolution electron microscope image of a grain boundary segment in as-hot-pressed ABC-SiC. The amorphous intergranular film (IGF), with a typical $1 \mathrm{~nm}$ width, can be recognized. Al-O-Si-C was detected in these IGFs with in situ EDS; oxygen most likely originated from unavoidable surface oxidation of the SiC starting powder. 20 to 30 grain boundary films were examined using high-resolution electron microscopy, and about $90 \%$ were found to be amorphous in the as-pressed samples. Quantitative EDS nanoprobe analysis of more than 20 IGFs determined the statistical mean value of the $\mathrm{Al}$ site density $\left(\mathrm{N}_{\mathrm{Al}}{ }^{\mathrm{GB}}\right)$ of $17.6 \pm 8.8 \mathrm{~nm}^{-3}$ in the amorphous grain boundary films. Here $\mathrm{N}_{\mathrm{Al}}{ }^{\mathrm{GB}}$ follows from the determination of the total $\mathrm{Al}$ excess per unit area of the IGF, $\Gamma_{\mathrm{Al}}$, so that $\mathrm{N}_{\mathrm{Al}}{ }^{\mathrm{GB}}=\Gamma_{\mathrm{Al}} / w$, where $w$ denotes the IFG width which can be measured in high-resolution TEM images. The EDS determination of $\Gamma_{\mathrm{Al}}$ requires knowledge of the foil thickness and the electron beam probe diameter [32]. The fairly large standard deviation implied that the $\mathrm{Al}$ content in grain boundary films was influenced by other constituents. In fact, in the dissolution-reprecipitation grain coarsening mechanism for the $\mathrm{ABC}-\mathrm{SiC}, \mathrm{SiC}$ dissolved into the liquid phase at hotpressing temperature. About one-third of the grain boundary films analyzed with EDS were found to contain significant Si and C, since the Si and C EDS peak intensities from 
IGFs were considerably stronger than those acquired from the neighboring $\mathrm{SiC}$ grains. Furthermore, chemical reactions among $\mathrm{Si}, \mathrm{C}, \mathrm{Al}, \mathrm{B}$, and $\mathrm{O}$ formed various secondary phases $[21,23]$ which are likely to subsequently affect the local $\mathrm{Al}$ content in the IGFs.

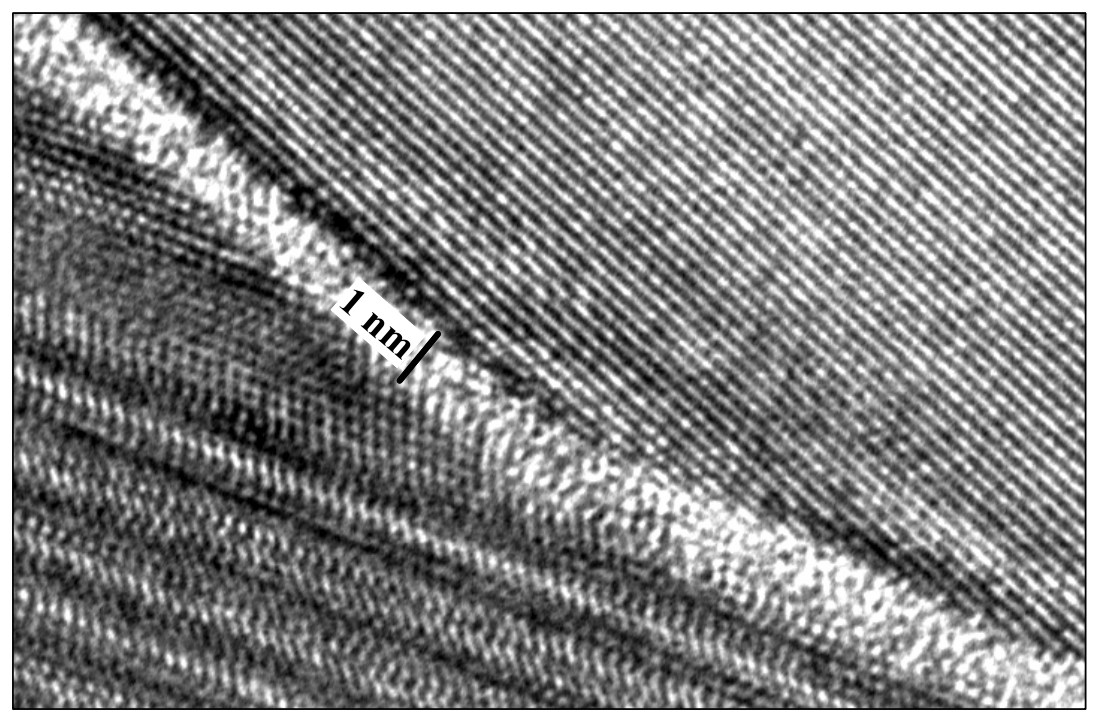

Fig. 1: High-resolution electron micrograph showing a grain boundary film between two $\mathrm{SiC}$ grains in ashot-pressed ABC-SiC. The boundary width is about $1 \mathrm{~nm}$.

Fig. 2a shows a typical grain boundary structure in an ABC-SiC sample annealed at $1500^{\circ} \mathrm{C}$, in Argon, for 7 days. In contrast to the prevalence of amorphous IGFs in aspressed samples, more than $85 \%$ grain boundary films after annealing above $1100^{\circ} \mathrm{C}$ had crystallized. Detailed high-resolution imaging and nanoprobe EDS quantification revealed that one of the intergranular crystalline phases was an $\mathrm{Al}_{2} \mathrm{OC}-\mathrm{mSiC}$ solid solution, with $\mathrm{m}$ values ranging from near 0 to as high as $\sim 22$. These solid solutions showed a $2 \mathrm{H}$-wurtzite structure (hexagonal unit cell, $\mathrm{a}=3.1 \AA, \mathrm{c}=5.0 \AA$ ) [22-23]. The crystallized films usually form epitaxially on the $\mathrm{SiC}$ (0001) habit plane of the adjoining matrix grains, when this plane is available. After the $1500^{\circ} \mathrm{C}$ annealing and cooling, a piece of the same sample was reheated to $1900^{\circ} \mathrm{C}$ for 5 min, in argon. Fig. $2 \mathrm{~b}$ and Fig. $2 \mathrm{c}$ show two types of grain boundary films after the $1900^{\circ} \mathrm{C}$ treatment. Apparently, the grain boundary film shown in Fig. 2b is disordered, compared to the crystalline IGF in Fig. 2c. 
EDS confirmed the continued presence of the Al in the IGFs. About $25 \%$ of the IGFs which crystallized at $1500^{\circ} \mathrm{C}$, were re-melted at $1900^{\circ} \mathrm{C}$ within 5 min.

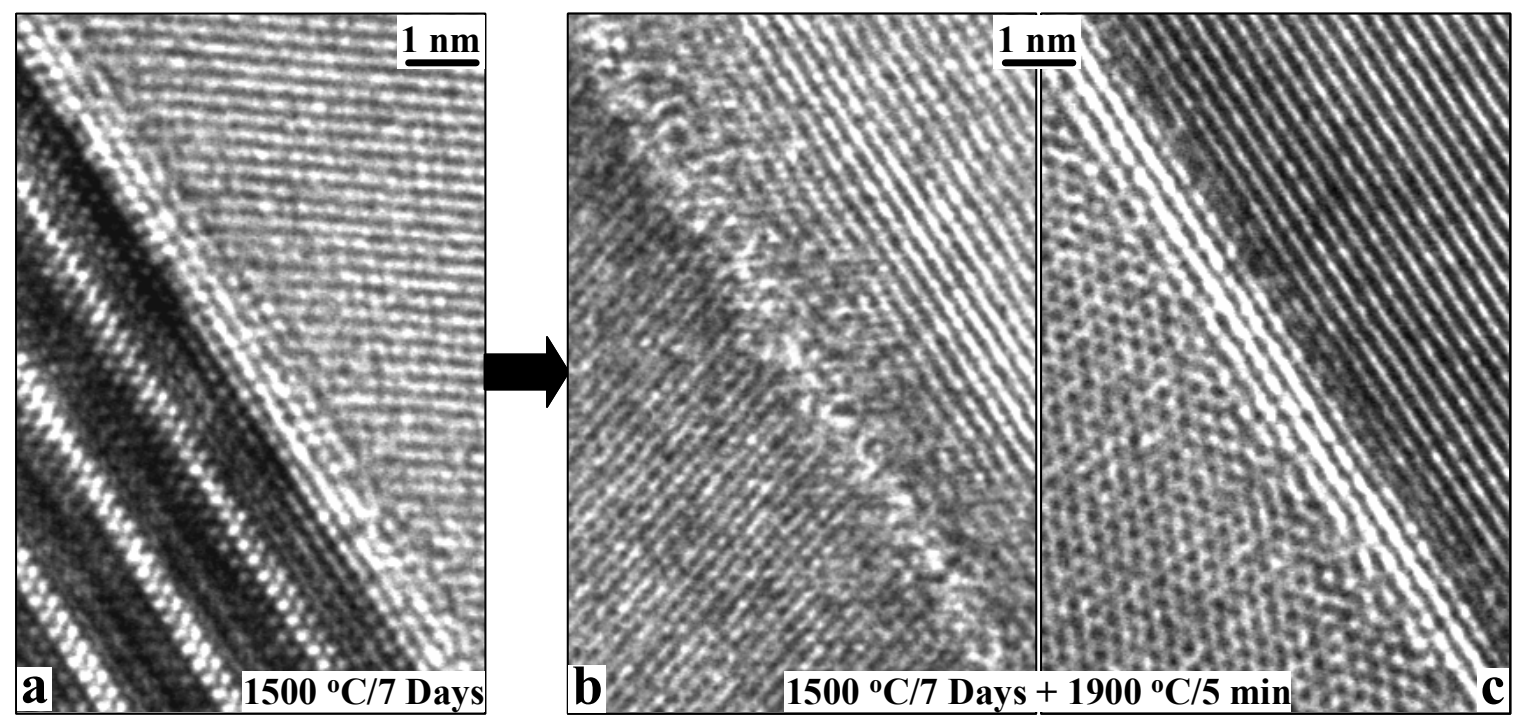

Fig. 2: (a), High-resolution image showing typical crystalline grain boundary structure after annealing at $1500^{\circ} \mathrm{C}$. The subsequent heating to $1900^{\circ} \mathrm{C}$ re-melted some crystalline grain boundary films such as the one shown in (b), but many grain boundary films remained crystalline, as shown in (c).

The width at grain boundary can be measured from high-resolution electron viewgraphs. Alternatively, it can be found by analyzing the $\mathrm{Al}$ profile across the grain boundary, since Al site density in the grain boundary films was more than 10 times higher than inside the SiC matrix grains. However, because of the amorphouscrystalline-amorphous transformations in the grain boundary films at elevated temperatures, it is more helpful to compare the widths of the amorphous layers, which can be directly measured using high-resolution electron microscopy. The measurement is straightforward for amorphous IGFs like those shown in Fig. 1 and Fig. 2b. For crystalline grain boundary films, the IGF width was taken to be zero, so that their fraction could be represented in the statistical data.

Fig. 3 shows the statistical data for the width distribution of the amorphous grain boundary layers in the as-hot-pressed, annealed $\left(1000-1500^{\circ} \mathrm{C}\right)$, and $1900^{\circ} \mathrm{C}$-treated $\mathrm{ABC}$ $\mathrm{SiC}$ samples. The mean values of the grain boundary widths are also marked, they are $1.3 \pm 0.6 \mathrm{~nm}, 0.9 \pm 0.3 \mathrm{~nm}$, and $0.7 \pm 0.2 \mathrm{~nm}$ for the as-hot-pressed, annealed, and $1900^{\circ} \mathrm{C}$ - 
treated samples, respectively. For the as-hot-pressed samples, the amorphous IGF widths range between $0.6 \mathrm{~nm}$ and $2.75 \mathrm{~nm}$, peaking at $\sim 1 \mathrm{~nm}$. After annealing above $1000^{\circ} \mathrm{C}$, more than $80 \%$ of the 30 to 40 examined grain boundaries crystallized; these were recorded as a zero-amorphous width fraction. Following the $1900^{\circ} \mathrm{C}$ heating, the fraction of crystalline (zero-amorphous width) IGFs dropped to about $60 \%$ out of 20 to 30 IGFs examined. It is intriguing to note that the thinner IGFs, less than $\sim 0.8 \mathrm{~nm}$, appeared to have been more readily converted back to the amorphous state. It is quite obvious that the annealing between 1000 and $1500^{\circ} \mathrm{C}$ not only crystallized nanoscale intergranular films, but that such structural change may be reversed at $1900^{\circ} \mathrm{C}$. The precise nature of these films has been shown to have profound effects on the macroscopic mechanical properties of the $\mathrm{SiC}[24-26,30,31]$.

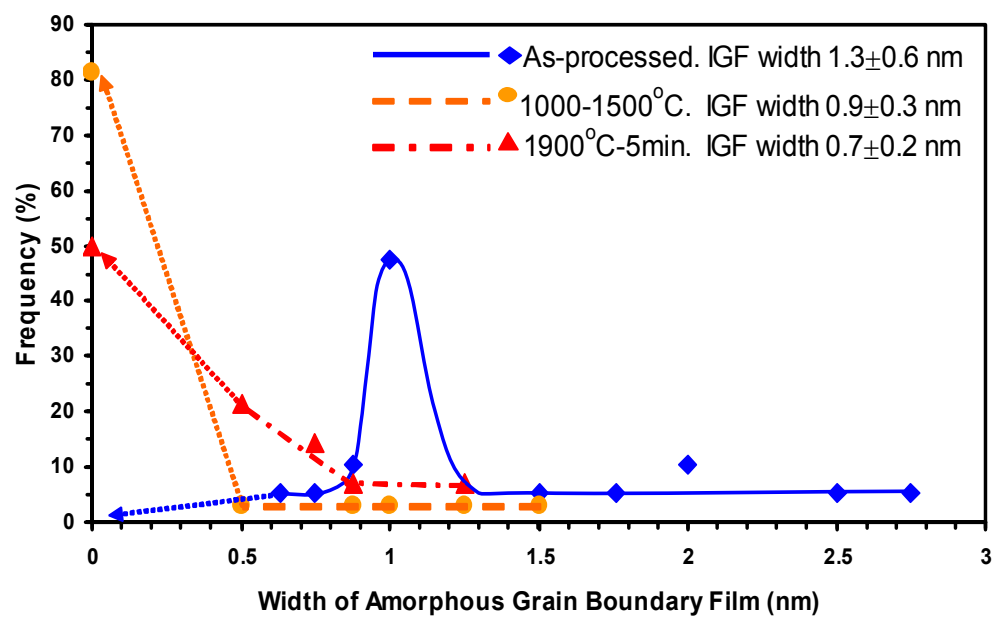

Fig. 3: Statistical width distribution of amorphous grain boundary layers for as-processed, annealed between 1000 and $1500^{\circ} \mathrm{C}$, and annealed at 1500 followed by a brief $1900^{\circ} \mathrm{C}$ treatment $\mathrm{ABC}-\mathrm{SiC}$, respectively. Mean values for grain boundary widths are also marked for the three cases.

In addition to the IGFs between two $\mathrm{SiC}$ grains, secondary phases were also observed at $\mathrm{SiC}$ three grain junctions. Fig. 4 shows a crystalline $\mathrm{Al}_{2} \mathrm{O}_{3}$ particle in a triplejunction pocket. It was noticed that, in contrast to the majority of the amorphous IGFs in 
as-processed samples, most triple-junction phases, with few exceptions, were crystalline. In addition to $\mathrm{Al}_{2} \mathrm{O}_{3}$ phase, various crystalline phases including $\mathrm{Al}_{4} \mathrm{C}_{3}, \mathrm{Al}_{8} \mathrm{~B}_{4} \mathrm{C}_{7}, \mathrm{Al}_{4} \mathrm{O}_{4} \mathrm{C}$, and Al-O-C-B phases were also identified at triple-junctions, most of them showing low dihedral angles[21,23]. It is interesting to note that boron did not stay within the grain boundary films but was present in some of these secondary phases. Also, the rather broad range of secondary phases, and often totally different triple-junction phases even when in contact with the same IGFs, indicated that the system has not yet reached chemical equilibrium, in spite of the high processing temperatures.

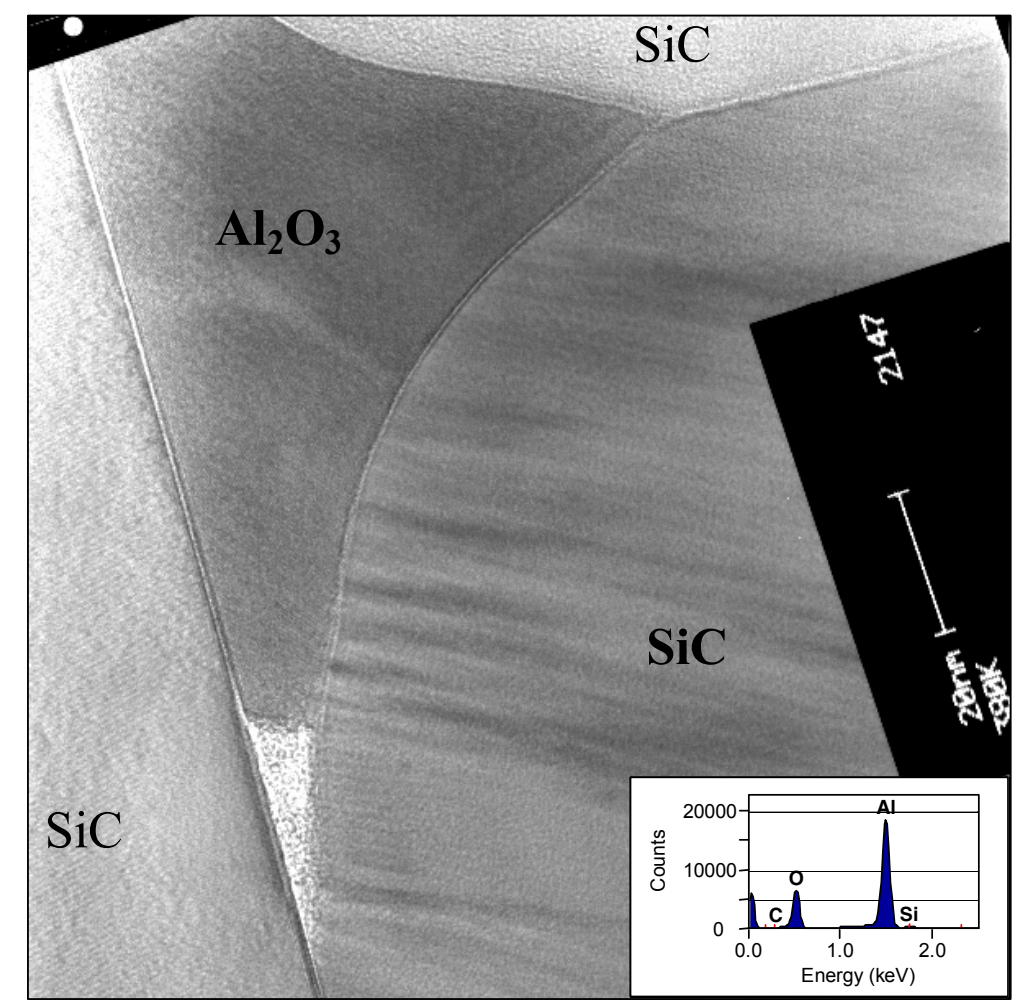

Fig. 4: Crystalline $\mathrm{Al}_{2} \mathrm{O}_{3}$ at a triple-junction pocket. The inset is the corresponding EDS spectrum.

Fig. 5 shows an interesting configuration, in which three intergranular phases are in contact. The phases in Pocket I, Pocket II, and the layer between the two pockets show a darker contrast compared to that of SiC grains because of the apparent difference in structure and composition. The particles in pocket I and II form low dihedral angles with the adjacent SiC, implying good wettability [23]. 


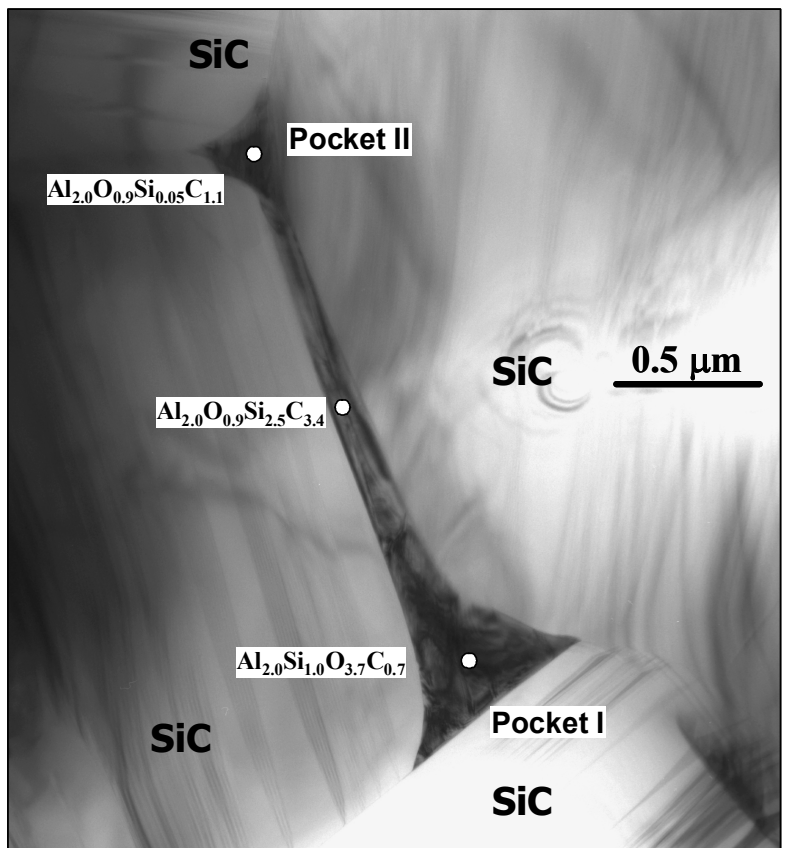

Fig. 5: Bright-field image showing two secondary phase particles in triple-junction pockets marked by Pocket I and Pocket II, respectively. A $~ 110 \mathrm{~nm}$ wide region between the Pockets I and II corresponds to a column-like intergranular phase particle with a triangular cross-section and viewed along a longitudinalnormal direction. Local EDS microanalyses were performed, and some analyzed spots and their corresponding compositions are marked.

EDS chemical analyses were performed on the three intergranular phases in Fig. 5, in which some (not all) spots are marked where EDS spectra were acquired using a 3.5 $\mathrm{nm}$ diameter probe. A typical EDS spectrum obtained from the $110 \mathrm{~nm}$ wide layer is shown in Fig. 6a. An Al-O-Si-C composition was detected, free of boron. Hydrocarbon surface contamination during the EDS spectrum acquisition caused a higher carbon peak than expected, but this contamination is not recognizable in Fig. 5 because it was imaged before EDS analysis. The presence of the hydrocarbon contamination was also evident in the EDS spectrum acquired from the adjacent SiC grain as shown in Fig. 6b, where the $\mathrm{C}$ to $\mathrm{Si}$ atom ratio was found to be 2.3 times higher than the stoichiometric ratio. Note that the EDS spectrum in Fig. $6 \mathrm{~b}$ was acquired about $50 \mathrm{~nm}$ away from the $110 \mathrm{~nm}$ wide intergranular layer, close enough to provide identical acquisition conditions as for 
spectrum in Fig. 6a. Therefore, the $\mathrm{SiC}$ grain bulk could be used as an internal standard to make a correction for the carbon content in the neighboring areas.
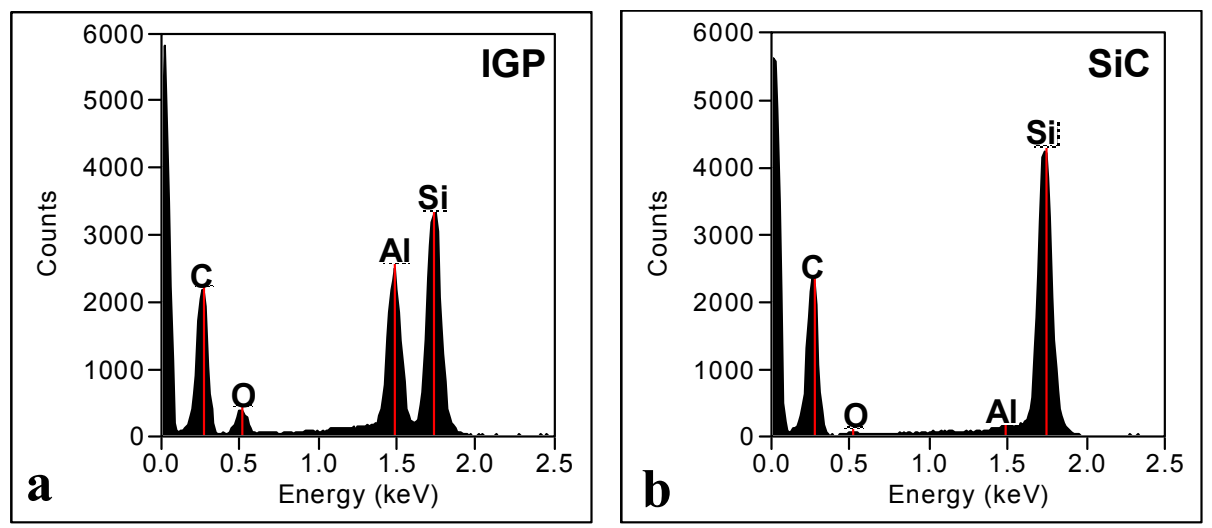

Fig. 6: EDS spectra acquired from (a), intergranular phase (IGP) between Pocket I and Pocket II; and (b), inside the $\mathrm{SiC}$ matrix.

$\mathrm{Al}$ and $\mathrm{Si}$ site densities in the $110 \mathrm{~nm}$ wide intergranular phase (IGP), $\mathrm{N}_{\mathrm{Al}}{ }_{\text {IGP }}$ and $\mathrm{N}_{\mathrm{Si}}{ }^{\text {IGP }}$, were determined using the ratio between Al- and Si-peak intensities:

$$
\begin{aligned}
& N_{A l}{ }^{I G P}=k_{A l S i} \frac{A_{S i}}{A A l} \frac{I_{A l}{ }^{I G P}}{I_{S i}{ }^{G}} \times N_{S i}{ }^{G} \\
& N_{S i}{ }^{I G P}=\frac{I_{S i}{ }^{I G P}}{I_{S i}{ }^{G}} \times N_{S i}{ }^{G}
\end{aligned}
$$

where $\mathrm{k}_{\mathrm{AlSi}}$ denotes the k-factor, $\mathrm{A}_{\mathrm{Si}}$ and $\mathrm{A}_{\mathrm{Al}}$ the atomic weight, $\mathrm{I}_{\mathrm{Al}}{ }_{\mathrm{IGP}}$ and $\mathrm{I}_{\mathrm{Si}}{ }^{\mathrm{IGP}}$ the $\mathrm{Al}$ and $\mathrm{Si}$ peak intensities in EDS spectra from the $110 \mathrm{~nm}$ wide intergranular phase, $\mathrm{I}_{\mathrm{Si}}{ }^{\mathrm{G}}$ the Si peak intensity from the $\mathrm{SiC}$, and $\mathrm{N}_{\mathrm{Si}}{ }^{\mathrm{G}}$ the site density of $\mathrm{Si}$ in SiC. The EDS analyses were performed at multiple spots along the secondary phase layer to get the mean values. On average, we obtained $\mathrm{N}_{\mathrm{Al}}^{\text {IGP }}=13.8 \mathrm{~nm}^{-3}$, and $\mathrm{N}_{\mathrm{Si}}^{\text {IGP }}=17.0 \mathrm{~nm}^{-3}$. The content of other constituent elements in the intergranular phase can be determined using the same method. The composition was determined to be close to $\mathrm{Al}_{2} \mathrm{OC}-2.5 \mathrm{SiC}$, a solid solution phase similar to that reported in Al-O-Si-C systems [10,33-35]. This is a $2 \mathrm{H}$-wurtzite structure with structures and lattice parameters similar to those of the $\alpha-\mathrm{Al}_{2} \mathrm{OC}$ or $2 \mathrm{H}-\mathrm{SiC}$ [33]. In fact, the electron diffraction pattern taken from the wide intergranular layer demonstrated 
a crystal structure consistent with the $\alpha^{\prime}-\mathrm{Al}_{2} \mathrm{OC}$, a variant of the $\alpha-\mathrm{Al}_{2} \mathrm{OC}$ phase with long-range order [36]. It is possible that the actual $\mathrm{SiC}$ content could be lower than 2.5 in the $\mathrm{Al}_{2} \mathrm{OC}-2.5 \mathrm{SiC}$ phase, since it could not be excluded that the incident electron beam also sampled the surrounding $\mathrm{SiC}$ grains.

Fig. 7a and Fig. 7b show EDS spectra obtained from Pocket I and Pocket II, respectively, marked in Fig. 5. Both phases are Al-O-Si-C-based. Quantitative analysis determined the composition of the Pocket I particle to be $\mathrm{Al}_{2.0} \mathrm{Si}_{1.0} \mathrm{O}_{3.7} \mathrm{C}_{0.7}$, which could also be written as $5.7 \mathrm{Al}_{2} \mathrm{O}_{3} \cdot 2 \mathrm{SiO}_{2} \cdot 3.7 \mathrm{SiC}$. This composition actually implies an Al-rich mullite phase. Once again, the $\mathrm{SiC}$ component was possibly from unavoidable sampling of some of the adjacent $\mathrm{SiC}$ grains. It was found that the Si content decreased sharply at the corner of the Pocket I particle, where the composition was closer to $\mathrm{Al}_{2} \mathrm{O}_{3}$. According to Kriven et al., a high $\mathrm{Al}_{2} \mathrm{O}_{3}$ content in mullite results in the precipitation of $\alpha-\mathrm{Al}_{2} \mathrm{O}_{3}$ as the primary phase [37]. This is consistent with the observations in the present study. The composition of the particle in Pocket II was determined to be essentially $\mathrm{Al}_{2} \mathrm{OC}$ (Fig. 7b). These EDS results provide illustration that intergranular phases may be different even when they are adjacent to each other.
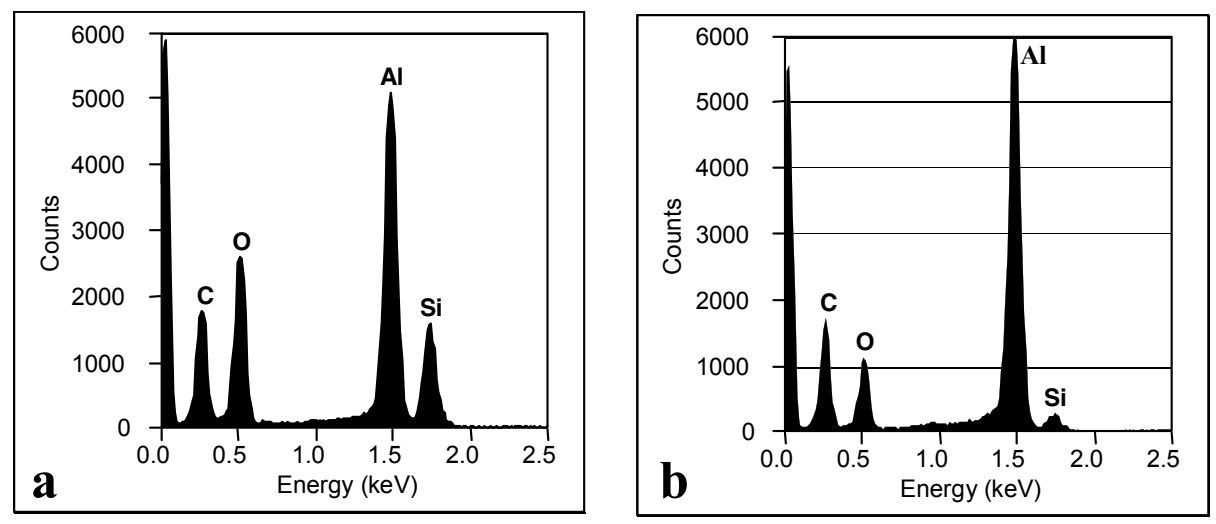

Fig. 7: EDS spectra acquired from (a), Pocket I; and (b), Pocket II, respectively (see Fig. 5). The corresponding acquisition locations are marked in Fig. 5.

The mullite phase determined by EDS for the Pocket I particle was confirmed by electron diffraction. Fig. 8 shows a selected-area electron diffraction pattern obtained from the central area of the Pocket I. The pattern shows the $[010]^{*}$ zone-axis projection 
of a $3 \mathrm{Al}_{2} \mathrm{O}_{3} \cdot 2 \mathrm{SiO}_{2}(3: 2)$ mullite-derived structure. The projected unit cell is outlined, and the (200) and (001) main reflections are marked. Incommensurate satellites were recognized between these main reflections, resembling ' $d$ ' or 'e' modulations reported by Cameron [38]. According to Cameron, an incommensurate superlattice appeared when the molar ratio between $\mathrm{Al}_{2} \mathrm{O}_{3}$ and $\mathrm{SiO}_{2}$ falls between 2.15 - 3.17 [38], due to the ordering of oxygen vacancies [38-39]. Our EDS quantification revealed a molar ratio of 2.9, consistent with the observed superlattice structure.

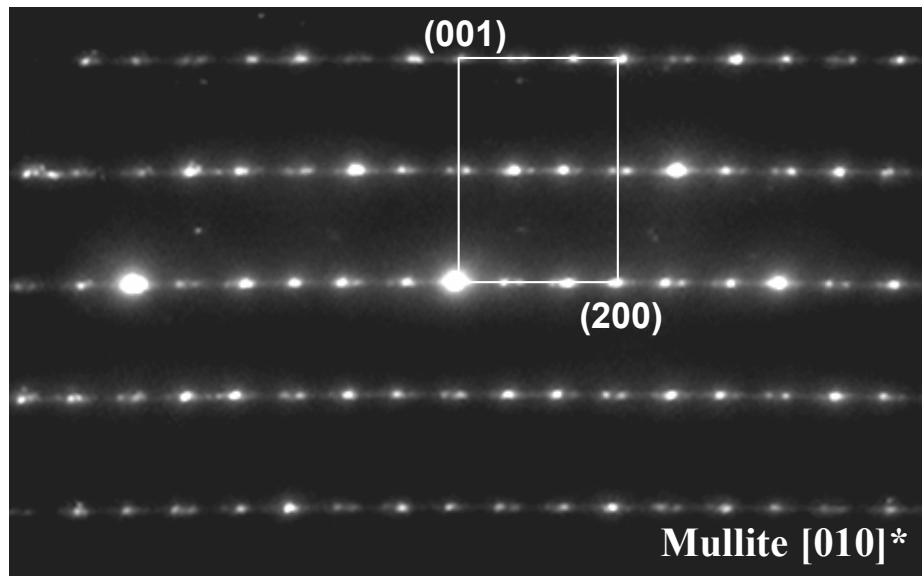

Fig. 8: Selected-area electron diffraction pattern taken from the central area of Pocket I. The pattern reveals a mullite [010]* projection with incommensurate satellites among the main reflections.

\section{4: Discussion}

The formation of various Al-based secondary phases and the Al-O-Si-C IGFs was a consequence of the liquid-phase sintering of the Al-B-C-SiC system. Al melted at about $660^{\circ} \mathrm{C}$, and $\mathrm{B}$ and $\mathrm{C}$ were mixed with molten $\mathrm{Al}$. Chemical reactions between $\mathrm{Al}$, $\mathrm{B}, \mathrm{C}$ and $\mathrm{SiO}_{2}$ oxide layers on $\mathrm{SiC}$ grain surface took place at elevated temperatures. $\mathrm{SiC}$ also dissolved into the liquid. The resulting secondary phases were identified in the present and previously published papers, including $\mathrm{Al}_{2} \mathrm{O}_{3}, \mathrm{Al}_{4} \mathrm{C}_{3}$, mullite, $\mathrm{Al}_{2} \mathrm{OC}-\mathrm{SiC}$, $\mathrm{Al}_{2} \mathrm{OC}, \mathrm{Al}_{4} \mathrm{O}_{4} \mathrm{C}, \mathrm{Al}_{8} \mathrm{~B}_{4} \mathrm{C}_{7}$, and Al-O-B-C [21,23]. Among these phases, those that do not contain boron can be represented in the quaternary phase diagram shown in Fig. 9. The observed Al-O-Si-C amorphous IGFs and their crystallized $\mathrm{Al}_{2} \mathrm{OC}-\mathrm{SiC}$ variants after annealing suggest the inclusion of an $\mathrm{Al}-\mathrm{O}-\mathrm{Si}-\mathrm{C}$ liquid domain in the quaternary diagram, 
as shown in Fig. 9. The $\mathrm{Al}_{2} \mathrm{OC}$ crystalline phase can coexist with liquid at $1900^{\circ} \mathrm{C}$ [10,40-41]. Occasionally, nanoscale clusters presumably composed of the $\mathrm{Al}_{2} \mathrm{OC}$ or $\mathrm{SiC}$ chemical species were observed in some wide (e.g. $3 \mathrm{~nm}$ ) amorphous grain boundary films [22]. EDS chemical analyses indicated that about two-third amorphous films analyzed had a low Si content, while the remainder had compositions as marked in the liquid zone between $\mathrm{Al}_{2} \mathrm{OC}$ and $\mathrm{SiC}$ in Fig. 9. Under suitable conditions, such as at sufficiently high temperatures, the formation of a $\mathrm{Al}_{2} \mathrm{OC}-\mathrm{SiC}$ solid solution was preferred in the $\mathrm{Al}-\mathrm{O}-\mathrm{Si}-\mathrm{C}$ system, presumably because $\mathrm{SiC}$ can stabilize the $\mathrm{Al}_{2} \mathrm{OC}$ structure [10,33-34]. Experimentally we found that when crystallized after prolonged annealing at $1100-1500^{\circ} \mathrm{C}$, a $2 \mathrm{H}$-wurtzite structure with $\mathrm{Al}_{2} \mathrm{OC}$ or $\mathrm{Al}_{2} \mathrm{OC}-\mathrm{mSiC}$ compositions was formed [22].

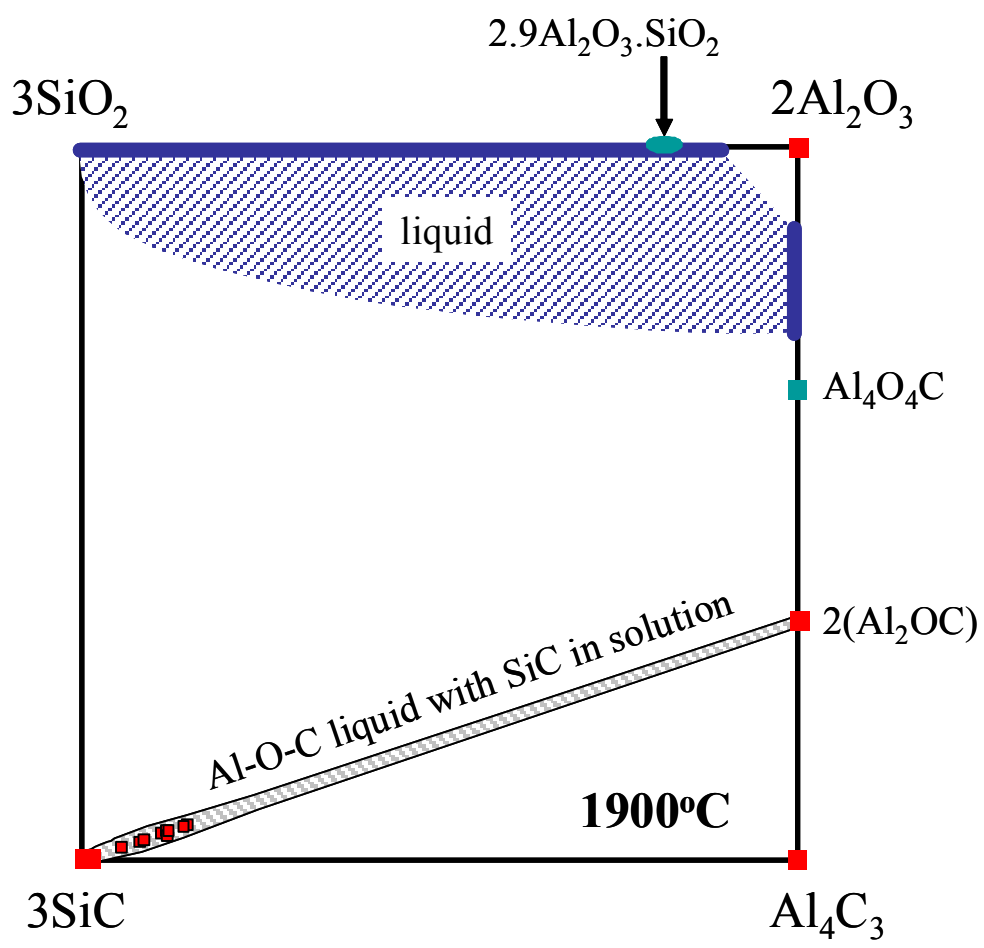

Fig. 9: Proposed quaternary phase diagram showing the intergranular phases formed in ABC-SiC.

Secondary phases experimentally identified, and $\mathrm{Al}_{2} \mathrm{OC}-\mathrm{SiC}$ liquid phase zone at $1900^{\circ} \mathrm{C}$ were marked. Within the $\mathrm{Al}_{2} \mathrm{OC}-\mathrm{SiC}$ liquid phase domain, experimentally determined, Si-containing compositions have been marked by squares. Mullite and $\mathrm{Al}_{4} \mathrm{O}_{4} \mathrm{C}$ were likely formed when cooling from $1900^{\circ} \mathrm{C}$.

The images in Fig. 2 and data shown in Fig. 3 demonstrate that upon heating to $1900^{\circ} \mathrm{C}$, at least $25 \%$ of the crystallized grain boundary films tended to be re-melted. 
The preferential conversion of the thinner grain boundaries to the amorphous state is interesting, and may be the result of the more ready re-absorption of $\mathrm{Al}$ from the thinner grain boundaries into the adjacent $\mathrm{SiC}$ grains. Lowering the $\mathrm{Al}$ content in IGF phases indeed tends to lower their melting point.

\section{Summary}

Intergranular phases in hot-pressed $\mathrm{ABC}-\mathrm{SiC}$ were studied using TEM. Statistical study of grain boundary films using high-resolution electron microscopy revealed that about $90 \%$ of the IGFs in as-hot-pressed $\mathrm{SiC}$ possessed a vitreous structure, with a mean width of $1.3 \mathrm{~nm}$. After annealing in argon, between 1000 to $1500^{\circ} \mathrm{C}, 85 \%$ grain boundary films examined showed a crystalline structure with a mean width of $0.9 \mathrm{~nm}$. The width distributions of the amorphous grain boundary layers were determined for samples with and without annealing. At least 25\% crystallized grain boundary films re-melted when subjected to $1900^{\circ} \mathrm{C}$ for a brief dwell of $5 \mathrm{~min}$, the IGFs with a width below about $0.8 \mathrm{~nm}$ apparently more readily converted than the thicker ones. A possible cause may be the more effective re-absorption of $\mathrm{Al}$ from the thinner grain boundaries into the adjacent $\mathrm{SiC}$ grains at high temperatures, which would tend to lower the melting point of the IGFs.

$\mathrm{Al}_{2} \mathrm{O}_{3}, \mathrm{Al}_{2} \mathrm{OC}-\mathrm{SiC}$, and mullite crystalline phases were newly identified at triplejunction pockets in as-hot-pressed $\mathrm{SiC}$. A quaternary $3 \mathrm{SiC}-\mathrm{Al}_{4} \mathrm{C}_{3}-2 \mathrm{Al}_{2} \mathrm{O}_{3}-3 \mathrm{SiO}_{2}$ phase diagram for $1900^{\circ} \mathrm{C}$ was derived to represent all boron-free phases identified in the present and earlier publications. $\mathrm{An}_{2} \mathrm{Al}_{2} \mathrm{OC}-\mathrm{SiC}$ liquid domain in the phase diagram is proposed based on the analysis of the IGFs.

\section{Acknowledgment:}

This work was supported by the Director, Office of Science, Office of Basic Energy Sciences, Division of Materials Sciences and Engineering of the U.S. Department of Energy under Contract No. DE-AC03-76SF0098. Part of this work was made possible through the use of the National Center for Electron Microscopy facility at the Lawrence Berkeley National Laboratory. Thanks are due to Qing Yang for her help in processing the $\mathrm{SiC}$ samples. 


\section{References}

[1] Alliegro RA, Coffin LB, Tinklepaugh JR. J Am Ceram. Soc 1956;39: 386.

[2] Prochazka S, Scanlan RM. J Am Ceram Soc 1975; 58: 72.

[3] Williams RM, Juterbock BN, Shinozaki SS, Peters CR, Whalen T. Am. Ceram Soc Bull 1985; 64: 1385.

[4] Nagano T, Kaneko K, Zhan GD, Mitomo M. J Am Ceram Soc 2000; 83: 2781.

[5] Hamminger R, Grathwohl G, Thummler F. J Mater Sci 1983; 18: 3154.

[6] Lane JE, Carter CH, Davis RF. J Am Ceram Soc 1988; 71: 281.

[7] Lange FF. J Mater Sci 1975; 10: 314.

[8] Omori M, Takei H. J Am Ceram Soc 1982; 65: C-923.

[9] Tanaka H, Inomata Y, Hara K, Hasegawa H. J Mater Sci Lett 1985; 4: 315.

[10] Huang JL, Hurford AC, Cutler RA, Virkar AV. J Mater Sci Lett 1986; 21: 1448.

[11] Mulla MA, Krstic VD. Am Ceram Soc Bull 1991; 70: 439.

[12] Padture NP. J Am Ceram Soc 1994; 77: 519.

[13] Tanaka H, Zhou Y. J Mater Res 1999; 4: 518.

[14] Lin BW, Imai M, Yano T, Iseki T. J Am Ceram Soc 1986; 69: C-67.

[15] Misra AK. J Am Ceram Soc 1991; 74: 345.

[16] Zhou Y, Tanaka H, Otani S, Bando Y. J Am Ceram Soc 1999; 82: 1959.

[17] Cao JJ, MoberlyChan WJ, De Jonghe LC, Gilbert CJ, Ritchie RO, J Am Ceram Soc 1996; 79: 461.

[18] MoberlyChan WJ, Cao JJ, De Jonghe LC, Acta Mater 1998; 46: 1625. 
[19] Hamminger R, Grathwohl G, Thummler F. J Mater Sci 1983; 18: 353.

[20] Sigl L, Kleebe HJ. J. Am Ceram Soc 1993; 76: 773.

[21] MoberlyChan WJ, De Jonghe LC. Acta Mater 1998; 46: 2471.

[22] Zhang XF, Sixta ME, De Jonghe LC. J Am Ceram Soc 2000; 83: 2813.

[23] Zhang XF, Sixta ME, De Jonghe LC. J Am Ceram Soc 2001; 84: 813.

[24] Chen D, Gilbert CJ, Zhang XF, Ritchie RO. Acta Mater 2000; 48: 6594.

[25] Chen D, Zhang XF, Ritchie RO. J Am Ceram Soc 2000; 83: 2079.

[26] Chen D, Sixta ME, Zhang XF, De Jonghe LC, Ritchie RO. Acta Mater 2000; 48: 4599.

[27] Zhang XF, Sixta ME, De Jonghe LC. J Mater Sci 2001; 36: 5447.

[28] Ritchie RO, Chen D, Zhang XF., Int. J Mater Prod Tech 2001; 1: 331.

[29] Zhang XF, Sixta ME, De Jonghe LC. Defect and Diffusion Forum 2000; 186-187: 45.

[30] Sixta ME, Zhang XF, De Jonghe LC. J Amer Ceram Soc 2001; 84: 2022.

[31] Zhang XF, Lee GY, Chen D, Ritchie RO, De Jonghe LC. J Am Ceram Soc 2003; 86: 1770 .

[32] Zhang XF, Yang Q, De Jonghe LC, Zhang Z. J Micros 2002; 207: 58.

[33] Cutler IB, Miller PD, Rafaniello W, Park HK, Thompson DP, Jack KH. Nature 1978; 275: 434.

[34] Babonneau F, Soraru GD, Thorne KJ, Mackenzie JD. J Am Ceram Soc 1991; 74 : 1725 .

[35] Westwood AD, Michael JR, Notis MR. J Micros 1992; 167: 287. 
[36] Yokokawa H, Dokiya M, Fujishige M, Kamayama T, Ujiie S, Fukuda K. J Am Ceram Soc 1982; 65: C-40.

[37] Kriven WM, Pask JA. J Am Ceram Soc 1983; 66: 649.

[38] Cameron WE. Am Mineral 1977; 62: 747.

[39] Nakajima Y, Ribbe PH. Am Mineral 1981; 66: 142.

[40] Foster LM, Long G, Hunter MS. J Am Ceram Soc 1956; 39: 1.

[41] Lihrmann JM, Zambetakis T, Daire M. J Am Ceram Soc 1989; 72: 1704. 


\section{Figure Captions}

Fig. 1: High-resolution electron micrograph showing a grain boundary film between two $\mathrm{SiC}$ grains in as-hot-pressed ABC-SiC. The boundary width is about $1 \mathrm{~nm}$.

Fig. 2: (a), High-resolution image showing typical crystalline grain boundary structure after annealing at $1500^{\circ} \mathrm{C}$. The subsequent heating to $1900^{\circ} \mathrm{C}$ re-melted some crystalline grain boundary films such as the one shown in (b), but many grain boundary films remained crystalline, as shown in (c).

Fig. 3: Statistical width distribution of amorphous grain boundary layers for asprocessed, annealed between 1000 and $1500^{\circ} \mathrm{C}$, and annealed at 1500 followed by a brief $1900^{\circ} \mathrm{C}$ treatment $\mathrm{ABC}-\mathrm{SiC}$, respectively. Mean values for grain boundary widths are also marked for the three cases.

Fig. 4: Crystalline $\mathrm{Al}_{2} \mathrm{O}_{3}$ at a triple-junction pocket. The inset is the corresponding EDS spectrum.

Fig. 5: Bright-field image showing two secondary phase particles in triple-junction pockets marked by Pocket I and Pocket II, respectively. A $~ 110 \mathrm{~nm}$ wide region between the Pockets I and II corresponds to a column-like intergranular phase particle with a triangular cross-section and viewed along a longitudinal-normal direction. Local EDS microanalyses were performed, and some analyzed spots and their corresponding compositions are marked.

Fig. 6: EDS spectra acquired from (a), intergranular phase (IGP) between Pocket I and Pocket II; and (b), inside the SiC matrix. 
Fig. 7: EDS spectra acquired from (a), Pocket I; and (b), Pocket II, respectively (see Fig. 5). The corresponding acquisition locations are marked in Fig. 5.

Fig. 8: Selected-area electron diffraction pattern taken from the central area of Pocket I. The pattern reveals a mullite [010]* projection with incommensurate satellites among the main reflections.

Fig. 9: Proposed quaternary phase diagram showing the intergranular phases formed in ABC-SiC. Secondary phases experimentally identified, and $\mathrm{Al}_{2} \mathrm{OC}-\mathrm{SiC}$ liquid phase zone at $1900^{\circ} \mathrm{C}$ were marked. Within the $\mathrm{Al}_{2} \mathrm{OC}-\mathrm{SiC}$ liquid phase domain, experimentally determined, Si-containing compositions have been marked by squares. Note that mullite and $\mathrm{Al}_{4} \mathrm{O}_{4} \mathrm{C}$ were likely formed when cooling from $1900^{\circ} \mathrm{C}$. 